\title{
Protección de datos personales, privacidad y vida privada: la inquietante búsqueda de un equilibrio global necesario
}

\author{
María Solange Maqueo Ramírez* \\ Jimena Moreno González** \\ Miguel Recio Gayo***
}

\begin{abstract}
RESUMEN
La protección de datos personales, como un derecho fundamental autónomo del derecho a la vida privada, ha tenido un desarrollo asimétrico en los diferentes sistemas de derechos bumanos. A pesar de la rápida evolución de la tecnología, la globalización de la economía y la digitalización de las relaciones humanas, aún no hay un nivel común de protección de datos en el mundo. La sentencia del Tribunal de Justicia de la Unión Europea, que declara la invalidez de la decisión de la Comisión Europea sobre el Acuerdo de Puerto Seguro UE-EE.UU., es solo un ejemplo de las diferentes aproximaciones en el tema. Este artículo pretende contribuir a generar algunos estándares internacionales en la protección de datos personales.
\end{abstract}

Datos personales - privacidad y vida privada - derechos humanos

\section{Data Protection, Privacy and Private Life: The Challenging Search of a Needed Global Balance}

\begin{abstract}
Data protection, as an autonomous fundamental right from the right of a private life, has had an asymmetric development in the different buman rights systems. Despite of the rapid evolution of technology, the globalization of the economy and the digitalization of the human relationships, there is not a common level of data protection all around the world. The judgement of the Court of Justice of the European Union, that declares invalid the European Commission Decision on the EU-US Safe Harbor Agreement, is just only an example of the different approaches to the subject. This paper aims to contribute to generate some international standards for the protection of personal data.
\end{abstract}

Personal data - privacy and private life - human rights

* Doctora en Derecho, Universidad de Salamanca, España. Profesora Investigadora de la División de Estudios Jurídicos del Centro de Investigación y Docencia Económicas (CIDE). Correo electrónico: maria. maqueo@cide.edu

** Maestra en Derecho, Instituto Tecnológico Autónomo de México (ITAM). Secretaria General del Centro de Investigación y Docencia Económicas (CIDE). Correo electrónico: jimena.moreno@cide.edu

*** Maestro en Protección de Datos, Transparencia y Acceso a la Información, Universidad CEU-San Pablo (España), y DEA (LLM) en Derecho de la Propiedad Intelectual, George Washington University Law School (EE.UU.). Correo electrónico: miguelrecio@miguelrecio.com

Artículo recibido el 8 de febrero de 2016 y aceptado para su publicación el 1 de marzo de 2017. 


\section{INTRODUCCIÓN}

$\mathrm{E}$ n materia de protección de datos personales, 2015 puede ser recordado como el año en el que se produjo un momento álgido en el escenario internacional, particularmente entre la Unión Europea y los Estados Unidos de América, que puntualiza la necesidad de contar con estándares comunes de protección entre países. Lo anterior se desprende del fallo del Tribunal de Justicia de la Unión Europea (en adelante, TJUE) que declaró inválido ${ }^{1}$, después de 15 años de funcionamiento, el llamado Acuerdo de Puerto Seguro ${ }^{2}$. Es posible observar que mediante este Acuerdo la Comisión Europea avalaba la transferencia de datos personales entre empresas de la Unión Europea y de los Estados Unidos de América, por considerar que dicho Acuerdo cumplía con un nivel adecuado de protección de datos.

Este caso en particular pone de manifiesto las diferencias en los distintos niveles de protección de la persona respecto del tratamiento de sus datos personales que, además de representar un trato desigual para los individuos, conlleva, a su vez, obstáculos importantes para el flujo de información, a veces tan necesario para el intercambio comercial y la cooperación internacional. La realidad actual es la de diferencias sustantivas, ya sea por la inexistencia de normatividad en algunos países o por las aproximaciones divergentes que se han seguido y que, en la práctica, pueden tener efectos negativos al crear notables desencuentros y, en buena medida, obstaculizar una protección efectiva de las personas.

En ese sentido, este trabajo pretende abordar el problema del desarrollo asimétrico, tanto normativo como jurisprudencial, del derecho a la protección de datos personales desde una perspectiva internacional, en el entendido de que ello, a su vez, se proyecta en una importante diferenciación entre países y regiones de todo el mundo. Esto nos lleva a cuestionarnos en qué consisten dichas asimetrías y cuáles son los criterios que permitirían la adopción de estándares comunes que sean aceptables entre países y regiones, si es que no es posible acordar un instrumento supranacional común. Ello, a su vez, implica la necesidad de considerar las razones por las cuales resultaría conveniente dicha estandarización. Es importante decir que las respuestas a estas interrogantes parten de la hipótesis de que en el ámbito internacional y, concretamente, en los sistemas internacionales de derechos humanos, existen disparidades en el reconocimiento del derecho a la protección de datos personales que poco han abonado a resolver esta situación, lo que genera desconfianza debido a la ausencia de niveles comunes de protección de la persona en su derecho a la protección de datos personales.

${ }^{1}$ Sentencia del Tribunal de Justicia (Gran Sala), de 6 de octubre de 2015, en el asunto C-362/14, Caso Schrems.

2 Decisión 2000/520/CE de la Comisión, de 26 de julio de 2000, con arreglo a la Directiva 95/46/ CE del Parlamento Europeo y del Consejo, sobre la adecuación de la protección conferida por los principios de puerto seguro para la protección de la vida privada y las correspondientes preguntas más frecuentes, publicadas por el Departamento de Comercio de Estados Unidos de América. Publicada en el Diario Oficial de la Unión Europea L 215, de 25 de agosto de 2000. 
Es por ello que la búsqueda de un equilibrio global conlleva la necesidad de establecer una hoja de ruta que tome como referencia las principales aportaciones que, desde una perspectiva internacional, se han desarrollado en torno a la protección de datos personales y en su relación con el derecho a la vida privada, con el objeto de establecer aquellos parámetros que sirvan de guía para dar un próximo paso en el fortalecimiento de la protección de la persona respecto del tratamiento de su información y, con ello, evitar injerencias indebidas, sea del sector privado o, más grave aún, del sector público, que incidan en una vulneración de su privacidad.

Desde un punto de vista metodológico es admisible observar que adoptamos una aproximación diacrónica que nos permite seguir el desarrollo evolutivo del derecho a la protección de datos personales en su relación con el derecho a la vida privada, en los distintos sistemas internacionales de derechos humanos (incluido el ámbito específico de la Unión Europea). Para tales efectos se parte de la recopilación, análisis y sistematización de fuentes documentales a partir de los instrumentos y criterios internacionales más relevantes en la materia. En ese sentido, nuestro enfoque pretende, más que hacer una construcción teórica de los derechos en juego, identificar aquellos aspectos que podrían ser necesarios para generar estándares comunes con un alcance global.

\section{VIDA PRIVADA Y PROTECCIÓN DE DATOS PERSONALES}

Definir el derecho a la vida privada no es una tarea fácil ${ }^{3}$. De hecho, existe pleno consenso entre los tribunales internacionales de derechos humanos en el sentido de que se trata de un concepto amplio, no susceptible de definiciones exhaustivas, y cuyo contenido es más extenso que el del derecho a la privacidad ${ }^{4}$. De tal forma que se reconoce que el derecho a la vida privada y la privacidad no son sinónimos ${ }^{5}$, a pesar de que el primero tiene un alcance mucho mayor que, en consecuencia, comprende al segundo. Si

${ }^{3}$ Cfr. Informe del Relator Especial de la ONU acerca de la promoción y protección del derecho a la libertad de opinión y expresión, de 17 de abril de 2013, numeral 21.

${ }^{4}$ CIDH, Caso Fernández Ortega y Otros vs. México, Sentencia de Fondo (Excepción Preliminar, Fondo, Reparaciones y Costas), de 30 de agosto de 2010, párr. 129; CIDH, Caso Rosendo Cantú y Otra vs. México, Sentencia de Fondo (Excepción Preliminar, Fondo, Reparaciones y Costas), de 31 de agosto de 2010, párr. 119; CIDH, Caso Artavia Murillo y Otros (Fecundación in vitro) vs. Costa Rica, Sentencia de Fondo (Excepción Preliminar, Fondo, Reparaciones y Costas, de 28 de noviembre de 2012, párr. 143); TEDH, Caso Amann v. Switzerland, Sentencia de 16 de febrero de 2000, párr. 65, entre otros.

${ }^{5}$ Cfr. Piñar Mañas, J. L., “¿Existe privacidad?”, en Protección de Datos Personales, Compendio de lecturas y legislación, Tiro Corto Editores, México, 2010; Miller, A. R., The Assault on Privacy: Computers, Data Banks, and Dossiers, University of Michigan Press, 1971; Roagna, I., "Protecting the right to respect for private and family life under the European Convention on Human Rights", en Council of Europe Human Rights Handbook, Strasbourg, 2012, p. 12; y Kikelly, Ú., "The right to respect for private and family life. A guide to the implementation of Article 8 of the European Convention on Human Rights", Human Rights Handbook, núm. 1, Strasbourg, 2003. 
bien la delimitación entre ambos excede los alcances de este trabajo ${ }^{6}$, nos centraremos exclusivamente en el análisis del derecho de la vida privada (en el entendido de que la privacidad es parte de la misma), en relación con el derecho a la protección de los datos personales ${ }^{7}$.

\section{Reconocimiento en convenios y otros instrumentos internacionales}

El derecho a la vida privada ha sido consagrado como un derecho humano tanto en el Sistema Universal de Derechos Humanos como en los sistemas regionales (específicamente en los sistemas europeo e interamericano). Por lo que hace al Sistema Universal, esto es, con un alcance global, la Declaración Universal de los Derechos Humanos de 1948 (artículo 12), el Pacto Internacional de Derechos Civiles y Políticos de 1966 (artículo 17), la Convención Internacional sobre la protección de los derechos de todos los trabajadores migratorios y de sus familiares de 1990 (artículo 14) y la Convención sobre los Derechos del Niño de 1989 (artículo 16), lo contemplan prácticamente en los mismos términos. Asimismo, el derecho a la vida privada goza de un reconocimiento expreso tanto en el ámbito interamericano, mediante el artículo 11.2 de la Convención Americana sobre Derechos Humanos (Pacto de San José), como en el ámbito europeo, por medio del Convenio para la Protección de los Derechos y Libertades Fundamentales (también llamado Convención Europea de Derechos Humanos) en su artículo 8.

Cuestión distinta ocurre por lo que hace al derecho a la protección de datos personales, toda vez que estos instrumentos internacionales carecen de una referencia expresa al mismo. De hecho, en 1980, la Asamblea Parlamentaria del Consejo de Europa recomendó al Comité de Ministros, que a la vista de la aproximación que estaban adoptando varios Estados miembros de la actual Unión Europea en cuanto a legislar en materia de protección de datos personales, estudiase la posibilidad de incluir en la Convención Europea de Derechos Humanos una referencia al mismo, idea que fue rechazada por "no ser el momento adecuado" para ello, debido a la falta de experiencia en la materia y los avances hacia la aprobación del llamado Convenio 108 que, por entonces, era un borrador muy avanzado, en cuanto al derecho a la protección de datos personales.

Otros convenios e instrumentos internacionales, fundamentalmente regionales y con un alcance limitado por estar dirigidos solo a ciertos países, contemplan expresamente el derecho a la protección de datos personales y establecen en su texto una relación estrecha con el derecho a la privacidad. Al respecto es posible mencionar las Directrices de la

${ }^{6}$ En la práctica, hay menciones a la privacidad y a la vida privada como un mismo derecho humano. Sobre el particular véase la Resolución 68/167, 21 de enero de 2014, el derecho a la privacidad en la era digital, aprobada por la Asamblea General de la Organización de Naciones Unidas (ONU) el 18 de diciembre de 2013, misma que se refiere en español al "derecho humano a la privacidad" pero utiliza también el término vida privada, consagrado en los artículos 12 de la Convención Universal de Derechos Humanos y 17 del Pacto Internacional de Derechos Civiles y Políticos.

${ }^{7}$ A causa de que la privacidad puede concebirse como parte del derecho a la vida privada, aquella también se relaciona con el derecho a la protección de datos personales. 
Organización para la Cooperación y el Desarrollo Económicos (OCDE) sobre protección de la privacidad y flujos transfronterizos de datos, adoptadas inicialmente en 1980 y actualizadas en el 2013. De acuerdo con las mismas, estas "suponen la unanimidad internacional sobre las guías generales para la recogida y gestión de información personal". Su objetivo, si bien recoge los principios que informan la protección de datos personales, consiste en adoptar estándares mínimos para garantizar la privacidad, ello a pesar de que carece de un carácter vinculante. De tal forma que en este documento la protección de datos personales adquiere un carácter instrumental para dotar de efectividad el derecho a la privacidad.

Asimismo, el Convenio (108) del Consejo de Europa, de 28 de enero de 1981, para la protección de las personas respecto del tratamiento automatizado de datos de carácter personal, establece en su artículo $1^{\circ}$ que tiene por objeto proteger "a cualquier persona física sean cuales fueren su nacionalidad o su residencia, el respeto de sus derechos y libertades fundamentales, concretamente su derecho a la vida privada, respecto del tratamiento automatizado de los datos de carácter personal correspondientes a dicha persona ("protección de datos")". Se trata de un instrumento vinculante, abierto incluso a la firma o ratificación por Estados que no son parte del Consejo de Europa, siempre que se cumplan con los requisitos que el propio Convenio 108 establece.

Ahora bien, será en el marco de la Unión Europea donde el derecho a la protección de los datos personales encuentra su máximo desarrollo normativo. Acerca del particular resulta interesante mencionar la Directiva 95/46/CE, misma que establece en su Considerando 10 que "las legislaciones nacionales relativas al tratamiento de datos personales tienen por objeto garantizar el respeto de los derechos y libertades fundamentales, particularmente del derecho al respeto de la vida privada reconocido en el artículo 8 del Convenio Europeo para la Protección de los Derechos Humanos y de las Libertades Fundamentales, así como en los principios generales del Derecho comunitario". Si bien el 27 de abril de 2016 se adoptó el Reglamento General de Protección de Datos que substituye a la Directiva 95/46/CE, el mismo sigue en la misma línea, con una aplicación directa para evitar divergencias entre los Estados miembros de la Unión Europea.

En un paso histórico para la protección de los datos personales en su calidad de derecho al más alto nivel normativo, se recoge expresamente tanto en el artículo 16 del Tratado de Funcionamiento de la Unión Europea (TFUE) como en la Carta de los Derechos Fundamentales de la Unión Europea. Esta última lo contempla, en su artículo 8, de manera separada del derecho a la vida privada (previsto en el artículo 7 de la propia Carta). Es así que se establece de manera específica su autonomía, sin perjuicio de la relación que se establezca entre ambos derechos ${ }^{8}$.

${ }^{8}$ Otras disposiciones relativas a la protección de datos personales en el ámbito de la Unión Europea pueden encontrarse respecto del sector de las comunicaciones electrónicas, de las propias instituciones y organismos de la Unión Europea o en el ámbito policial y judicial, Al respecto véanse, respectivamente, la Directiva 2002/58/CE del Parlamento Europeo y del Consejo, de 12 de julio de 2002, relativa al tratamiento de los datos personales y a la protección de la intimidad en el sector de las comunicaciones electrónicas, la Directiva 2009/136/CE del Parlamento Europeo y del Consejo, de 25 de noviembre de 2009, por el que se 
Es esencial decir que el artículo 8 de la citada Carta de los Derechos Fundamentales establece que el tratamiento de los datos personales tiene que realizarse conforme a unos criterios o principios que lo legitimen y que deberá existir una autoridad de control independiente que se encargue de supervisar el respeto de las normas acerca de la materia.

Así, de conformidad con lo anterior, puede decirse que el derecho a la protección de datos personales se ha desarrollado fundamentalmente en el ámbito europeo. Se consagra por primera vez en el Convenio 108 del Consejo de Europa, seguido por la Directiva 95/46/CE de la Unión Europea, como una proyección o faceta del derecho a la vida privada ${ }^{9}$. Sin embargo, desde entonces hasta la fecha, especialmente tras la adopción de la Carta de Derechos Fundamentales de la Unión Europea, este derecho adquiere vida propia, al margen del reconocimiento de que el tratamiento de datos personales que no cumpla con las condiciones de legitimidad aplicables, puede llegar a suponer una injerencia en la vida privada o la privacidad.

Este modelo europeo, también ampliamente desarrollado en el derecho interno de los países que lo conforman, ha sido una importante fuente de inspiración para diversos países del Continente Americano que, como en el caso de México, reconocen la protección de datos personales como un derecho humano diferenciado, aunque relacionado con el derecho a la vida privada. De ahí que, como veremos, sea necesario adoptar estándares comunes que excedan el ámbito nacional o, incluso, regional.

\section{Desarrollo de la jurisprudencia internacional}

El desarrollo jurisprudencial en los distintos sistemas internacionales de derechos humanos ha sido mucho más rico respecto del derecho a la vida privada que relativas al derecho a la protección de datos personales, no solo por su reconocimiento explícito en los instrumentos internacionales que les dan origen, sino además por su propia antigüedad.

De hecho, es valioso observar que hasta el momento la Corte Interamericana de Derechos Humanos (en adelante, $\mathrm{CIDH}$ ) no se ha pronunciado de manera específica en ningún caso respecto del derecho a la protección de datos personales, a pesar de que un gran número de países sujetos a su jurisdicción lo contemplan dentro de su propio

modifican la Directiva 2002/22/CE relativa al servicio universal y los derechos de los usuarios en relación con las redes y los servicios de comunicaciones electrónicas y el Reglamento (CE) no. 2006/2004 sobre la cooperación en materia de protección de los consumidores; el Reglamento (CE) no. 45/2001 del Parlamento Europeo y del Consejo, de 18 de diciembre de 2000, relativo a la protección de las personas físicas en lo que respecta al tratamiento de datos personales por las instituciones y los organismos comunitarios y a la libre circulación de estos datos, y; la Directiva (UE) 2016/680 del Parlamento Europeo y del Consejo, de 27 de abril de 2016, relativa a la protección de las personas físicas en lo que respecta al tratamiento de datos personales por parte de las autoridades competentes para fines de prevención, investigación, detección o enjuiciamiento de infracciones penales o de ejecución de sanciones penales, y a la libre circulación de dichos datos y por la que se deroga la Decisión Marco 2008/977/JAI del Consejo, de 27 de noviembre de 2008.

${ }^{9}$ Cfr. De Hert, P. y Gutwirth, S., "Data Protection in the Case Law of Strasbourg and Luxemburg: Constitutionalisation in Action”, en Gutwirth, Serge et al. (eds.), Reinventing Data Protection?, Springer, 2009, Cap. 1, Sección 1.1.2. 
derecho interno con el carácter de derecho humano. De tal forma que, como veremos, el desarrollo internacional de la protección de datos personales se produce a nivel regional y, fundamentalmente en Europa, a partir de la propia construcción expansiva del derecho a la vida privada hasta el reconocimiento de su propia autonomía.

\subsection{Criterios de la Corte Interamericana de Derechos Humanos}

En su sentido más tradicional, la CIDH ha puesto de manifiesto que el derecho a la vida privada implica una obligación negativa para el Estado. En un primer momento, ha establecido su vínculo con la inviolabilidad del domicilio. De tal forma que la intromisión en el domicilio familiar de las personas, sin el consentimiento de quienes lo habitan y sin autorización legal para ello, así como su propia destrucción, se consideran una violación grave, injustificada y abusiva en términos del artículo 11.2 de la Convención Americana de Derechos Humanos ${ }^{10}$.

Asimismo, la Corte considera que " $[$.... el ámbito de la privacidad se caracteriza por quedar exento e inmune a invasiones agresivas o arbitrarias por parte de terceros o de la autoridad pública”. Además, establece que las injerencias en la vida privada de las personas deben: (1) estar previstas en ley, (2) perseguir un fin legítimo, y (3) ser idóneas, necesarias y proporcionales. En otras palabras, los requisitos que han de cumplir los límites al derecho a la vida privada comprenden tanto el principio de proporcionalidad en términos de Alexy (compuesto por sus tres subprincipios: idoneidad, necesidad y proporcionalidad en sentido estricto $)^{11}$, como el principio de legalidad. En caso de no cumplir con estos requisitos, las injerencias se consideran contrarias a los términos de la propia Convención ${ }^{12}$. Al respecto, este Tribunal manifiesta que, a pesar de no señalarse explícitamente en el texto de la Convención, la vida privada extiende sus alcances más allá del domicilio y la correspondencia, incorporando otros aspectos como la intervención, monitoreo, grabación y divulgación de conversaciones por vía telefónica ${ }^{13}$. En ese sentido se reconoce que " $[1]$ a fluidez informativa que existe hoy coloca al derecho a la vida privada de las personas en una situación de mayor riesgo debido a las nuevas herramientas tecnológicas y su utilización cada vez más frecuente”. De ahí que el Estado deba "asumir un compromiso aún mayor, con el fin de adecuar a los tiempos actuales las formas tradicionales de protección del derecho a la vida privada" ${ }^{4}$.

${ }^{10} \mathrm{CIDH}$, Caso Masacres de Ituango vs. Colombia, Sentencia de Fondo, de 1 de julio de 2006, párr. 197; CIDH, Caso Escué Zapata vs. Colombia, Sentencia de Fondo (Reparaciones y Costas), de 4 de julio de 2007, párrs. 94 y 96. Más adelante, la CIDH retoma este criterio en el Caso Familia Barrios vs. Venezuela, Sentencia de Fondo (Reparaciones y Costas), de 24 de noviembre de 2011, párr. 140.

${ }^{11}$ Cfr. Alexy, Robert, "Constitutional Rights and Proportionality", Revus, Journal for constitutional theory and philosophy of law, núm. 22, 2014, p. 52.

${ }^{12}$ CIDH. Caso Tristán Donoso vs. Panamá, Sentencia de Fondo (Excepción Preliminar, Fondo, Reparaciones y Costas), de 27 de enero de 2009, párrs. 55 y 76.

${ }^{13}$ Idem. y CIDH, Caso Escher y Otros vs. Brasil, Sentencia de Fondo (Excepción Preliminar, Fondo, Reparaciones y Costas), de 6 de julio de 2009, párr. 114.

${ }^{14}$ Ibídem, párr. 115. 
Así, la Corte de manera consistente con sus resoluciones previas, manifiesta que "el concepto de vida privada es un término amplio no susceptible de definiciones exhaustivas". Sin embargo, este concepto comprende, entre otras cosas, "la vida sexual y el derecho a establecer y desarrollar relaciones con otros seres humanos". De tal forma que las violaciones sexuales vulneran la vida privada de las personas, toda vez que impiden "el control sobre sus decisiones más personales e íntimas y sobre las funciones corporales básicas" 15 .

En una concepción expansiva del derecho a la vida privada y su estrecha relación con otros derechos humanos reconocidos por la Convención Americana, la Corte señala que "la vida privada incluye la forma en que el individuo se ve a sí mismo y cómo y cuándo decide proyectar a los demás”. Asimismo, retoma los requisitos necesarios para considerar que una injerencia en la vida privada de las personas no se considere abusiva o arbitraria, señalando que tanto la idoneidad, la necesidad, como la proporcionalidad de las medidas adoptadas implican que sean "necesarias en una sociedad democrática" 16 .

Finalmente, en una resolución histórica relativa a la prohibición general de la fecundación in vitro concebida como una injerencia en la vida privada de las personas, la CIDH adopta de manera expresa criterios provenientes del Tribunal Europeo de Derechos Humanos, en el sentido de que el ámbito de protección del derecho a la vida privada va más allá del derecho a la privacidad. De manera textual, la Corte ahonda en el concepto de vida privada, mediante la adopción de criterios cuyo desarrollo corresponde al ámbito europeo:

La protección a la vida privada abarca una serie de factores relacionados con la dignidad del individuo, incluyendo por ejemplo la capacidad para desarrollar la propia personalidad y aspiraciones, determinar su propia identidad y definir sus propias relaciones personales. El concepto de vida privada engloba aspectos de la identidad física y social, incluyendo el derecho a la autonomía personal, desarrollo personal y el derecho a establecer y desarrollar relaciones con otros seres humanos y con el mundo exterior. La efectividad del ejercicio del derecho a la vida privada es decisiva para la posibilidad de ejercer la autonomía personal sobre el futuro curso de eventos relevantes para la calidad de vida de la persona. La vida privada incluye la forma en que el individuo se ve a sí mismo y cómo decide proyectarse hacia los demás, y es una condición indispensable para el libre desarrollo de la personalidad. [.... $]^{17}$

${ }^{15}$ CIDH, Caso Fernández Ortega vs. México, Sentencia de Fondo (Excepción Preliminar, Fondo, Reparaciones y Costas), de 30 de agosto de 2010, párr. 129 y Caso Rosendo Cantú y Otra vs. México, Sentencia de Fondo (Excepciones Preliminares, Fondo, Reparaciones y Costas), de 31 de agosto de 2010, párr. 119.

${ }^{16}$ CIDH. Caso Atala Riffo y Niñas vs. Chile, Sentencia de Fondo (Reparaciones y Costas), de 24 de febrero de 2012, párr. 162.

${ }^{17}$ CIDH, Caso Artavia Murillo y Otros ("Fecundación in vitro") vs. Costa Rica, Sentencia de Fondo (Excepciones Preliminares, Fondo, Reparaciones y Costas), de 28 de noviembre de 2012, párr. 143. 
Es posible decir que este fallo de la CIDH, mismo que retoma los criterios emitidos por su homóloga europea en materia del derecho a la vida privada, permite anticipar el desarrollo armónico de este derecho en ambos sistemas internacionales de derechos humanos. No obstante, su distanciamiento, por lo menos hasta la actualidad, se produce precisamente con la incorporación del derecho a la protección de datos personales y su relación con otros derechos humanos de frontera (como la libertad de expresión).

\subsection{Criterios de la Corte Europea de Derechos Humanos}

De manera similar a lo ocurrido en la CIDH, la Corte Europea de Derechos Humanos (o TEDH), en sus primeras resoluciones respecto del artículo 8 del Convenio Europeo de Derechos Humanos, se ocupa de posibles violaciones que suponen una interferencia del Estado en la vida privada y familiar de las personas. Especialmente el TEDH se ocupa, en un primer momento, de la vigilancia secreta de los Estados, por medio de la posible o efectiva interceptación de comunicaciones, por consideraciones de orden criminal o de seguridad nacional ${ }^{18}$. Basado en lo anterior, este Tribunal comienza a interpretar los requerimientos para considerar que las interferencias del Estado que presentan un riesgo para la vida privada y familiar de las personas cumplen con el artículo 8 del Convenio Europeo para la protección de los Derechos Humanos y las Libertades Fundamentales.

Así, el TEDH si bien admite que los Estados firmantes de la Convención tienen cierta discreción respecto de los términos en los que operan sus sistemas de vigilancia, no se trata de una discreción absoluta ${ }^{19}$. Para que la interferencia se apegue a los términos del citado artículo 8 es necesario que: (1) persiga un objetivo legítimo; (2) sea conforme con la ley, y (3) sea necesaria en una sociedad democrática. Todo ello implica la adopción de garantías adecuadas y efectivas contra los abusos que pudiera ocasionar la autoridad ${ }^{20}$.

Por lo que hace a la persecución de un fin legítimo, el Tribunal ha analizado varios casos en los que se considera que se cumple este requisito, por ejemplo, en la adopción de medidas para garantizar la seguridad nacional y la prevención del desorden o el delito e, incluso, posteriormente, en relación con la transferencia de datos de salud de una autoridad a otra para la decisión de las autoridades respecto de la asignación de recursos públicos $^{21}$, entre otros. Por su parte, el requerimiento de que la interferencia esté de acuerdo con la ley, supone, de acuerdo con el TEDH, que además de encontrar sustento en la legislación doméstica, es necesario considerar la calidad de la ley y su foreseeability, esto es, que contribuya a fortalecer el estado de derecho. Así, la Corte establece que el requerimiento de que la medida sea "de acuerdo con la ley" supone que existe una previsión legal previa y que la ley sea accesible y suficientemente clara respecto de las

18 TEDH, Klass and others v. Germany, Sentencia de 6 de septiembre de 1978, párr. 35 y ss.

19 Ibidem.

${ }^{20}$ THDE, Malone $v$. The United Kingdom, Sentencia de 2 de agosto de 1984, párr. 63 y ss. y TEDH, Kruslin v. France, Sentencia de 24 de abril de 1990, párr. 27 y ss., entre otros.

${ }^{21}$ TEDH, M. S. v. Sweden, Sentencia de 2 de agosto de 1997, párr. 32 y ss; y TEDH, Leander v. Sweden, Sentencia de 26 de marzo de 1987, párr. 48 y ss. 
circunstancias y condiciones en las que las autoridades están facultades para establecer estas interferencias, estableciendo a su vez medidas adecuadas de protección legal ${ }^{22}$. Finalmente, el requerimiento de que las interferencias sean necesarias en una sociedad democrática implica la identificación, dentro del ámbito más amplio del objetivo legítimo perseguido, de la necesidad social específica que deba abordarse, la proporcionalidad de la medida para alcanzar dicho objetivo legítimo y que existan razones relevantes y suficientes que la justifiquen en razón de otras posibles medidas ${ }^{23}$.

Un paso decisivo para que el Tribunal Europeo pudiera adentrarse a campos propios del derecho a la protección de datos personales, inicialmente referido al acceso a la propia información personal que consta en archivos públicos, fue el reconocimiento de que si bien el artículo 8 del Convenio Europeo tiene esencialmente por objeto proteger a los individuos en contra de interferencias arbitrarias por las autoridades públicas, también podría comprender obligaciones positivas del Estado inherentes al respeto efectivo de la vida privada y familiar, de tal forma que incluso la negativa para conceder acceso a la información personal del individuo debe analizarse, "por una autoridad independiente" bajo la óptica de los requerimientos que establece el artículo 8 antes indicados, con el fin de garantizar la aplicación del principio de proporcionalidad ${ }^{24}$. Al respecto, la Corte reconoce que el artículo 8 protege, entre otros intereses, el derecho al desarrollo personal, lo que incluye el derecho de recibir información relativa a su identidad personal, necesaria para conocer sus orígenes y entender su infancia y posterior desarrollo ${ }^{25}$.

Es esencial decir que las primeras referencias explícitas a la protección de los datos personales se presentan en el contexto de información sensible que contiene datos de salud $^{26}$. En un primer momento, la Corte Europea se cuestiona si las medidas que se impugnan -consistentes en obtener y mantener por un periodo la confidencialidad de información médica de una pareja infectada por VIH, misma que consta en el expediente de un juicio seguido en contra de uno de ellos por delitos de carácter sexual- fueron necesarias en una sociedad democrática. Al respecto, la Corte señala que la confidencialidad de los datos de salud es un principio vital en los sistemas legales de los Estados parte del Convenio. Es crucial, señala, no solo en el sentido de respeto a la privacidad de los pacientes, sino también para preservar su confianza en la profesión médica y en los servicios de salud en general. Además, estas consideraciones cobran especial relevancia cuando se trata de la confidencialidad de información relativa a una persona infectada de

${ }^{22}$ Ibidem.

${ }^{23}$ Grupo de Trabajo del Artículo 29 sobre la Protección de Datos, Dictamen 1/2014 sobre la aplicación de los conceptos de necesidad, proporcionalidad y la protección de datos en el sector de los organismos con funciones coercitivas, adoptado el 27 de febrero de 2014, p. 6 y ss.

${ }^{24}$ TEDH, Gaskin v. The United Kingdom, Sentencia de 7 de julio de 1989, párr. 49.

25 TEDH, Odièvre v. France, Sentencia de 13 de febrero de 2003, párr. 25 y ss. y X and Y v. Netherlands, Sentencia de 26 de marzo de 1985 , párr. 28 y ss.

26 TEDH, Z. v. Finland, Sentencia del 25 de febrero de 1997, párr. 72 y ss.; TEDH, M. S. v. Sweden, Sentencia de 2 de agosto de 1997, párr. 32 y ss. 
VIH, toda vez que la revelación de esta información puede afectar de manera dramática su vida privada y familiar, laboral y social, exponiéndola al oprobio y el ostracismo ${ }^{27}$.

Con posterioridad, la Corte reconoce explícitamente que la transferencia de datos de salud de una autoridad a otra, sin el consentimiento del paciente y que, a su vez, ha servido para diferentes propósitos, constituye una interferencia en el derecho al respeto de la vida privada y familiar del paciente. En ese sentido, la Corte establece que las medidas adoptadas para la comunicación de la información entre autoridades se deben analizar a la luz de los requerimientos previamente establecidos ${ }^{28}$.

De igual forma, bajo la idea de que el término de "vida privada" no debe ser interpretado de manera restrictiva, la Corte incluye dentro del ámbito de protección del multicitado artículo 8 , el almacenamiento de datos relativos a una persona, con independencia de si los mismos son o no sensibles, lo que, de acuerdo con el propio Tribunal, es consistente con el Convenio 108 del Consejo de Europa ${ }^{29}$. Asimismo, estas consideraciones se hacen extensivas al uso de la información, lo que incluye su divulgación por parte de las autoridades, y a la carencia de medios para refutar el contenido de dicha información ${ }^{30}$.

En sucesivas ocasiones, la Corte reitera las obligaciones positivas del Estado para proteger la vida privada de las personas que se derivan del párrafo 1 del artículo 8 del Convenio Europeo, lo que la lleva a considerar la posibilidad de que, incluso, la divulgación de información por parte de personas distintas a las autoridades, incluida la prensa y los medios de comunicación masiva, sea contraria a los términos de la Convención ${ }^{31}$. También dentro de este rubro, consistente en las obligaciones positivas que conlleva el citado artículo 8 del Convenio, el Tribunal reitera el deber de proporcionar a las personas "un procedimiento efectivo y accesible" para obtener el acceso a "información relevante y apropiada" de los archivos personales mantenidos por las autoridades ${ }^{32}$.

De esta forma, como se puede observar, el TEDH va perfilando la inclusión del derecho a la protección de datos personales en relación con el derecho a la vida privada. Incluso, ya establece en sus decisiones esta conexión al indicar textualmente que " $[1]$ a protección de datos de carácter personal juega un rol fundamental en el ejercicio del derecho al respeto de la vida privada y familiar consagrado en el artículo 8 de la Convención”. Acerca del particular se señala que el mero hecho de que la legislación interna facilite la oportunidad de reclamar indemnizaciones por daños y perjuicios por la revelación ilegal de los datos personales, no es razón suficiente para proteger la vida

${ }^{27}$ TEDH, Z. v. Finland, cit., párrs. 111 y 112. Sobre el particular también véase TEDH, I. v. Finland, Sentencia de 17 de octubre de 2008, párr. 35.

28 TEDH, M.S. v. Sweden, cit., párr. 32 y ss.

29 TEDH, Amann v. Switzerland, Sentencia de 16 de febrero de 2000, párr. 65.

30 TEDH, Rotaru v. Romania, Sentencia del 4 de mayo de 2000, párr. 46 y TEDH, Peck v. United Kingdom, Sentencia de 28 de enero de 2003, párr. 57 y ss.

31 TEDH, Von Hannover v. Germany (No. 2), Sentencia de 7 de febrero de 2012, párr. 74 y ss.; y Sciacca v. Italy, Sentencia de 11 de enero de 2005, párr. 27 y ss.

32 TEDH, Haralambie v. Romania, Sentencia de 27 de octubre de 2009, párr. 86. 
privada, es necesario que los Estados firmantes de la Convención provean de una protección "real y efectiva" que excluya cualquier posibilidad de acceso no autorizado ${ }^{33}$.

Lo anterior es consistente con la idea central de que el derecho a la vida privada "es un término amplio no susceptible de una definición exhaustiva, que comprende la integridad física y psicológica de una persona y puede comprender múltiples aspectos de la identidad de la persona, [....”34 . De ahí que desde esta perspectiva el alcance del término "dato personal" sea esencialmente amplio. De hecho, el Tribunal Europeo se ha referido a muy diversos ámbitos entre los que se incluye información relativa a una persona identificada o identificable que van desde el propio nombre, la fecha de nacimiento y el historial médico, hasta las huellas dactilares, muestras de células y elaboración de perfiles de ADN, entre otros ${ }^{35}$.

En virtud de los precedentes antes mencionados, es posible observar que existe cierto consenso entre la Corte Interamericana de Derechos Humanos y el Tribunal Europeo respecto del amplísimo alcance del derecho a la vida privada, fundamentalmente en el sentido de que el derecho a vida privada comprende múltiples aspectos de la identidad de las personas y de cómo deciden relacionarse con otros seres humanos. Sin embargo, podemos observar que el desarrollo del contenido y alcance de este derecho ha sido asimétrico, específicamente por lo que se refiere al reconocimiento explícito del derecho a la protección de datos personales. Mientras que la Corte Interamericana hasta el momento no se ha pronunciado al respecto, el Tribunal Europeo ha dado pasos significativos que permiten profundizar acerca de la noción misma del derecho a la protección de datos personales en su relación con el derecho a la vida privada. En concreto, el Tribunal de Estrasburgo reconoce que bajo el concepto de vida privada puede quedar amparada "toda información relativa a una persona física identificada o identificable”, esto es, con independencia de si se trata o no de información sensible que afecta la esfera más íntima de las personas, lo que a su vez es consistente con la amplia definición de "dato personal". De igual forma, en su jurisprudencia introduce la búsqueda de criterios interpretativos conformes con la normatividad específica en materia de protección de datos personales, como se puede observar en sus referencias al Convenio 108 del Consejo de Europa.

No obstante, es admisible advertir que la construcción del derecho a la protección de datos personales desde la perspectiva del Tribunal Europeo de Derechos Humanos aún se encuentra bajo la égida del derecho a la vida privada. Su carácter autónomo, en el ámbito internacional de los derechos humanos, se presenta con la Carta de Derechos Fundamentales y su interpretación jurisprudencial por parte del Tribunal de Justicia de la Unión Europea.

33 TEDH, B.B. v. France, Sentencia de 17 de diciembre de 2006, párr. 61.

34 TEDH, Axel Springer AG v. Germany, Sentencia de 7 de febrero de 2012, párr. 83.

35 TEDH, S. and Marper $v$. United Kingdom, Sentencia de 4 de diciembre de 2008, párr. 71; K.U. v. Finland, Sentencia de 2 de diciembre de 2008, párr. 41 y ss.; Khelili v. France, 18 de octubre de 2011, párr. 56; y, M.K. v. France, Sentencia de 18 de abril de 2013, párr. 29. 


\subsection{Criterios del Tribunal de Justicia de la Unión Europea}

El Tribunal de Justicia de la Unión Europea toma como base de interpretación no solo la Carta de Derechos Fundamentales de la Unión Europea, misma que ya reconoce de manera explícita y autónoma el derecho a la protección de datos personales, sino también la Directiva 95/46/CE antes citada, entre otros documentos normativos que regulan la protección de datos personales en la Unión Europea.

De esta forma, este Tribunal se adentra a cuestiones mucho más específicas para delinear los contornos del derecho a la protección de datos personales, que terminan por acentuar el carácter autónomo de este derecho frente al derecho a la vida privada, sin dejar de reconocer su estrecha vinculación. Entre otros asuntos, este Tribunal se ha ocupado de establecer criterios interpretativos en relación con la transferencia de datos a terceros países (no miembros de la Unión Europea), la conservación de datos relativos a comunicaciones electrónicas, la gestión de motores de búsqueda concebida como tratamiento de datos personales y los sistemas de videovigilancia operados por particulares ${ }^{36}$.

En un caso relevante para la interpretación de la Carta de Derechos Fundamentales en consonancia con los criterios emitidos por el TEDH, el TJUE establece que "el respeto a la vida privada en lo que respecta al tratamiento de los datos personales" se aplica a toda información sobre una persona física identificada e identificable y, además, que "las limitaciones al derecho a la protección de datos personales de carácter personal que pueden establecerse legítimamente corresponden a las toleradas en el contexto del artículo 8 del CEDH”. De tal forma que este órgano jurisdiccional, al referirse sobre quién puede ser titular del derecho a la protección de datos personales, reconoce que solo las personas físicas cuentan con esta facultad, pues "las personas jurídicas solo pueden acogerse a la protección de los artículos 7 y 8 de la Carta frente a dicha identificación en la medida en que en la razón social de la persona jurídica se identifique a una o varias personas físicas" ${ }^{37}$. Así, esta característica presenta una importante diferencia de alcance, en el contexto europeo, del derecho a la vida privada del Convenio y el derecho a la protección de datos personales reconocido en la Carta, toda vez que el ámbito de protección del primero alcanza efectivamente a las personas morales.

No obstante, el propio Tribunal ha reconocido que tratándose de "la protección de los derechos y las libertades fundamentales de las personas físicas, en particular su derecho a la intimidad, en lo que respecta al tratamiento de los datos personales", no es posible separar los casos de tratamiento de datos personales en dos categorías, a saber, una categoría en la que ese tratamiento sería examinado únicamente sobre la base del artículo 8 del Convenio Europeo y su interpretación jurisprudencial y otra categoría

${ }^{36} \mathrm{Al}$ respecto véanse las Sentencias del Tribunal de Justicia, de 8 de abril de 2014, en el asunto C-293, Caso Digital Rights Ireland y Seitlinger y otros, apartado 34 y ss.; de 13 de mayo de 2014, en el asunto C-131/12, Caso Google Spain y Google, apartado 36 y ss.; y, de 11 de diciembre de 2014, en el asunto C-212/13, Caso Ryneš, apartado 21.

${ }^{37}$ Sentencia del Tribunal de Justicia (Gran Sala), de 9 de noviembre de 2010, en los asuntos C-92/09, Caso Volker und Markus Schecke GbR y C-93/09, Caso Hartut Eifert, acumulados, apartado 53. 
en la que dicho tratamiento estaría sujeto a las disposiciones normativas de protección de datos personales en la Unión Europea ${ }^{38}$. De ahí que el TJUE reconozca la estrecha relación entre derechos, cuyo contenido puede ser en ocasiones coincidente.

Además, es factible considerar por lo que hace a la estrecha relación entre el derecho a la vida privada consagrado por el TEDH y la Carta de Derechos Fundamentales, que esta establece en su artículo 52, apartado 3, que "[e]n la medida en que la presente Carta contenga derechos que correspondan a derechos garantizados por el Convenio Europeo [...], su sentido y alcance serán iguales a los que les confiere dicho Convenio. Esta disposición no obstará a que el Derecho de la Unión conceda una protección más extensa”.

De igual forma, este Tribunal en diversas ocasiones ha tenido oportunidad de referirse al carácter independiente de las autoridades de control de los datos personales, que exige la Directiva 95/46/CE. Sobre este aspecto en particular, el Tribunal ha establecido que "[l]a garantía de independencia de las autoridades de control nacionales tratan de asegurar un control eficaz y fiable del respeto de la normativa en materia de protección de las personas físicas en lo que respecta al tratamiento de sus datos personales y debe interpretarse a la luz de dicho objetivo”. Todo ello implica que las autoridades de control actúen con objetividad e imparcialidad, esto es, libres de cualquier influencia externa, directa o indirecta, que pudiera poner en peligro de la tarea que les corresponde de lograr un justo equilibrio entre la libre circulación de los datos personales y el derecho a su vida privada (intimidad) ${ }^{39}$. Bajo estas consideraciones, el Tribunal constata que si bien la independencia funcional de las autoridades, "en el sentido de que no estén sujetas a instrucción alguna en el ejercicio de sus funciones", es una condición necesaria para garantizar el cumplimiento de sus tareas ${ }^{40}$, esta independencia funcional no basta por sí sola, toda vez que es necesario que la misma también se ejerza de manera indirecta, esto es, que pueda excluir toda forma de influencia que pudiera orientar las decisiones de la autoridad, como podría ser una relación de supervisión jerárquica ${ }^{41}$.

Es importante subrayar que precisamente la carencia de una autoridad de control independiente por parte de los Estados Unidos de América fue uno de los motivos que dio lugar a que el TJUE invalidara el Acuerdo de Puerto Seguro, al que nos hemos referido con anterioridad (apartados 41 y 42 de la Sentencia) ${ }^{42}$, mismo que pone de manifiesto la relevancia de homologar criterios en beneficio de las personas.

Por tanto, deben quedar claras tres ideas en relación con las autoridades de control o garantes de los derechos y libertades fundamentales, en particular por lo que se refiere

38 Sentencia del Tribunal de Justicia (Gran Sala), de 29 de junio de 2010, en el asunto C-28/08, Caso Bavarian Lager, apartado 61.

${ }^{39}$ Sentencia del Tribunal de Justicia (Gran Sala), de 9 de marzo de 2010, en el asunto C-518/07, Caso Comisión/Alemania, apartado 25 y ss.

${ }^{40}$ Sentencia del Tribunal de Justicia (Gran Sala), de 8 de abril de 2014, en el asunto 288/12, Caso Comisión/Hungría, apartado 51 y ss.

${ }^{41}$ Sentencia del Tribunal de Justicia (Gran Sala), de 16 de octubre de 2012, en el asunto C-614/10, Caso Comisión/Austria, apartado 42 y ss.

42 Caso Schrems, cit., apartados 41 y 42. 
a la protección de datos personales. La primera es que exista y que sea independiente. La segunda, que dichas autoridades de control puedan ejercer sus competencias de manera que se proteja de manera efectiva el derecho a la protección de datos personales. Y la tercera, que la ausencia de dichas autoridades de control impide el reconocimiento del nivel adecuado de protección de un país, con independencia de otros elementos previstos para su tutela.

La sentencia del TJUE que invalidó el Acuerdo de Puerto Seguro entre la Unión Europea y los Estados Unidos de América explica que “debe entenderse la expresión 'nivel de protección adecuado' en el sentido de que exige que ese tercer país garantice efectivamente, por su legislación interna o sus compromisos internacionales, un nivel de protección de las libertades y derechos fundamentales sustancialmente equivalente al garantizado en la Unión por la Directiva 95/46, entendida a la luz de la Carta" 43 y añade que "[a]unque los medios de los que se sirva ese tercer país para garantizar ese nivel de protección pueden ser diferentes de los aplicados en la Unión para garantizar el cumplimiento de las exigencias derivadas de esa Directiva entendida a la luz de la Carta, deben ser eficaces en la práctica para garantizar una protección sustancialmente equivalente a la garantizada en la Unión" ${ }^{44}$. Si bien el territorio donde se encuentran los datos personales es un factor a considerar para determinar si un país cumple con un nivel adecuado de protección, no es el único. El nacionalismo de datos ${ }^{45}$ no puede llevar a perder de vista que lo importante no es dónde están los datos personales, obviando otros mecanismos, como la regulación e, incluso, las normas corporativas vinculantes ${ }^{46}$ que son necesarias para facilitar la libre circulación de datos personales a nivel internacional.

\section{UN EQUILIBRIO GLOBAL ES NECESARIO Y POSIBLE}

\section{Asimetrías de protección}

El reconocimiento del derecho a la protección de datos personales en los instrumentos internacionales, así como su interpretación jurisprudencial, pone de manifiesto las asimetrías que se presentan por región por lo que hace a su reconocimiento y alcance.

Como se ha podido constatar de la jurisprudencia emitida por los tribunales internacionales, el desarrollo del derecho a la protección de datos personales se ha presentado

${ }^{43}$ Caso Schrems, cit., apartado 73.

${ }^{44}$ Idem., apartado 74.

${ }^{45}$ Cfr. Castro, Daniel, "The False Promise of Data Nationalism”, en The Information Technology E Innovation Foundation, diciembre, 2013; y, Gutiérrez, Horacio E. y Korn, Daniel, "Facilitando the Cloud: Data Protection Regulation as a Driver of National Competitiveness in Latin America", en Inter-American Law Review. University of Miami School of Law, vol. 45, issue 1, 2014.

${ }^{46}$ Sobre dichas normas vinculantes y las Reglas Transfronterizas de Privacidad véase el Common Referential for the Structure of the EU System of Binding Corporate Rules and APEC Cross Border Privacy Rules System. Disponible en: http://mddb.apec.org/Documents/2014/ECSG/ECSG1/14_ecsg1_013.pdf 
fundamentalmente en Europa, sea mediante su vínculo con el derecho a la vida privada, reconocido en el artículo 8 de la $\mathrm{CEDH}$, o de manera particularizada por medio del ámbito de la Unión Europea. El hecho de que la Carta de Derechos Fundamentales, de manera consistente con el Tratado de Funcionamiento de la Unión Europea, lo reconozca de forma autónoma y con un ámbito específico de protección, obliga a todos los Estados miembros de la Unión a adecuar su legislación doméstica al más alto nivel normativo y a adoptar los criterios que determinan su interpretación y alcance.

En términos generales, la base para garantizar una protección adecuada que se materialice en el control que la persona pueda tener sobre el tratamiento de sus datos personales, se constituye mediante unos criterios de legitimación, los principios de la protección de datos, la posibilidad de ejercer derechos por parte del titular de los datos y la supervisión, misma que puede concretarse en la tutela de la persona a la que se refieren los datos personales que son objeto de tratamiento, así como la atribución y el ejercicio de potestades de investigación y sanción por parte de una autoridad de control independiente. Si bien el TEDH se ha referido a algunos de estos aspectos en contextos específicos, la normatividad de la Unión Europea, así como los criterios que se han desarrollado sobre la misma, tanto en el ámbito jurisdiccional como no jurisdiccional (como es el caso del Grupo de trabajo del artículo 29 o, incluso, del llamado Grupo de Berlín, además por supuesto de las propias autoridades de control nacionales en la Unión Europea), han permitido establecer los contornos del derecho a la protección de datos personales.

Se trata, entonces, de garantías que tienen que darse de manera efectiva y que, al mismo tiempo, implican un claro compromiso europeo con el derecho humano a la protección de datos personales. Estas, a su vez, presentan un carácter transversal, cuyo alcance abarca cualquier ámbito o momento, con independencia de que el titular de los datos actúe en relaciones de subordinación (frente a las autoridades públicas) o de coordinación (frente a otros particulares).

Por tanto, la ausencia total o parcial de estas garantías, tanto desde un punto de vista formal, en cuanto a su reconocimiento en la legislación o mediante mecanismos de regulación sectorial o, incluso de autorregulación, como desde una perspectiva práctica, por lo que se refiere a la efectividad de las mismas, implica la imposibilidad en el ámbito europeo de reconocer un nivel de protección adecuado para quien carezca de las mismas.

Cuestión distinta ocurre en el ámbito americano y particularmente dentro del Sistema Interamericano de Derechos Humanos. Si bien ya existe una larga tradición que ampara el derecho a la vida privada, la protección de datos personales carece aún de una construcción propia, tanto normativa como jurisprudencial, a pesar de los incipientes esfuerzos y avances de la Organización de Estados Americanos $(\mathrm{OEA})^{47}$ y de la Red Iberoamericana de Protección de Datos (RIDP). Ello también, a pesar de que varios Estados parte del Sistema han adoptado, con una clara influencia europea, el derecho a

${ }^{47}$ Véase el informe 474/15 rev. 2, del Comité Jurídico Interamericano, sobre Privacidad y Protección de Datos Personales, de 26 de marzo de 2015. 
la protección de datos personales con un carácter de derecho humano autónomo, aunque interrelacionado con el derecho a la vida privada, cuyo alcance se proyecta tanto en el reconocimiento del derecho a la autodeterminación informativa de las personas, como del habeas data. Este es precisamente el caso de Argentina, Chile, Uruguay, México y Colombia, entre otros.

En el caso concreto de Argentina y Uruguay, es admisible decir que la Comisión Europea les ha otorgado el reconocimiento como países que efectivamente establecen un nivel adecuado de protección de datos personales, lo que incluso ha llevado a Uruguay a ser el primer y único país en Latinoamérica en haber procedido a la adhesión al Convenio 108 y su Protocolo Adicional, mismos que tienen por objeto establecer las reglas generales para garantizar el respeto a la vida privada (por lo que se refiere al tratamiento automatizado de datos de carácter personal) y simultáneamente la libre circulación de la información ${ }^{48}$.

\section{Necesidad de un equilibrio global}

La ausencia de criterios internacionales uniformes acerca del derecho a la protección de datos personales no solo dificulta la relación con Europa por lo que hace a los flujos de información entre autoridades y el sector privado, sino que además acentúa las diferencias conceptuales entre los diversos sistemas de derechos humanos, cuya característica fundamental debiera residir precisamente en su "universalidad".

La falta de estándares comunes entre regiones entorpece el cumplimiento de ciertos objetivos importantes para el progreso económico y social, el desarrollo del intercambio entre países y el bienestar de los individuos, como eliminar las restricciones en la libre circulación de los datos personales, falsear la competencia económica e impedir que las administraciones cumplan los cometidos que les incumben ${ }^{49}$, así como problemas de seguridad de los datos.

Además, no debemos olvidar que la protección de la persona por lo que hace al tratamiento de sus datos personales es un instrumento necesario para garantizar la protección de otros derechos humanos y libertades fundamentales, toda vez que redunda, a fin de cuentas, en la dignidad de la persona. Como se ha constatado en las diversas resoluciones del Tribunal Europeo (y en cierta medida en la CIDH), el tratamiento adecuado de la información personal -mismo que incluye su recogida, uso, acceso, divulgación, transferencia, etc.- resulta indispensable para garantizar la vida privada de las personas. Asimismo, se relaciona con otros derechos humanos como la igualdad y la no discriminación, toda vez que la revelación de información "sensible" puede dar lugar al aislamiento de la persona o, incluso, a tratos segregacionistas. De ahí que el

${ }^{48}$ Maqueo, M. y Moreno, J., "Implicaciones de una ley general en materia de protección de datos personales”, DT-DEJ del Centro de Investigación y Docencia Económicas, núm. 64, marzo de 2014, p. 3.

$49 \mathrm{Si}$ bien estas ideas se han desarrollado en el ámbito de las relaciones entre los países miembros de la Unión Europea, concretamente en la Directiva 95/46/CE en su considerando 7, lo cierto es que son extrapolables a las relaciones con otros países en un contexto propio de la globalización. 
derecho a la protección de datos personales busque tutelar a las personas, mediante el otorgamiento de un poder de control sobre su propia información, sujeto a ciertas restricciones susceptibles de ser valoradas bajo márgenes de apreciación que comprendan tanto los requisitos que permiten justificar una injerencia como la gravedad de la afectación respecto de otros derechos humanos.

Una cuestión adicional que es posible considerar para justificar la necesidad de generar estándares homogéneos a nivel global es el efecto que ello tendría en el fortalecimiento de la confianza en los usuarios de servicios o consumidores. La protección efectiva de la información personal, mediante el derecho sustantivo, la existencia de autoridades de control independientes, las normas procedimentales y sancionatorias, así como los mecanismos de cooperación adecuados, son la base para generar esta confianza, necesaria en todos los ámbitos, sea en las relaciones entre particulares y las Administraciones Públicas como respecto de los consumidores y proveedores de bienes y servicios que tratan datos personales.

Impulsar la confianza por medio de una protección adecuada, por tanto, depende, por una parte, de la adopción e implementación de diversas medidas tanto normativas como institucionales, y por otra parte, de que las mismas sean efectivas, lo que pasa por evaluar a lo largo del tiempo si responden a las circunstancias actuales en cada momento.

En este sentido, asegurar y proteger los derechos humanos y las libertades fundamentales, entre los que se encuentra el derecho a la protección de datos personales, debe ser una tendencia a considerar frente a los planteamientos ocurridos hasta hace apenas unas décadas, en el sentido de que aún no era el momento adecuado para reconocer este derecho en el texto del CEDH.

\section{Estándares comunes}

La generación de estándares comunes con un alcance global acerca de la protección de datos personales no solo es necesaria sino también posible, toda vez que sus cimientos ya han sido establecidos por el propio reconocimiento y desarrollo del derecho a la vida privada. A todo ello se añade el progresivo avance en la materia que se ha venido generando en algunos países del Continente Americano y, aunque con un alcance limitado, en el propio Sistema Interamericano de Derechos Humanos.

Ciertamente los mecanismos que permitan homologar estos estándares de protección adecuada pueden adquirir muy diversa naturaleza. No obstante, dos vías que consideramos pertinentes para tal fin, debido a su proyección y su carácter vinculante en el ámbito internacional, son, por una parte, la búsqueda de la adhesión al Convenio 108 y su Protocolo Adicional por aquellos países que, como México, aún no son parte del mismo y, por la otra, la adopción de criterios compatibles en los diversos Sistemas de Derechos Humanos. Esto último podría impulsarse con la solicitud de opiniones consultivas por parte de los países interesados o, a su vez, por los propios particulares que ven vulnerados sus derechos.

De acuerdo con todo lo anterior, algunos de los elementos que resultan clave para que la protección de la persona, por lo que hace al tratamiento de sus datos personales, 
sea efectiva son: (a) el establecimiento de principios y deberes que legitimen el tratamiento de los datos personales, consistentes con la evolución social y tecnológica; (b) el reconocimiento de los derechos de los interesados y los procedimientos para garantizar su ejercicio, con el fin de que se les permita un control efectivo respecto de su información, y; (c) la existencia de autoridades independientes de control, en el sentido de que sean ajenas a cualquier influencia externa, tanto directa como indirecta.

\section{CONCLUSIÓN}

El desarrollo evolutivo del derecho a la protección de datos personales desde una perspectiva internacional ha sido asimétrico, a pesar de la necesidad de generar estándares comunes consistentes con los riesgos que supone el desarrollo tecnológico y un mundo cada vez más global, con objetivos compartidos. La declaración de invalidez del Acuerdo de Puerto Seguro del Tribunal de Justicia de la Unión Europea es tan solo una manifestación más de este proceso desigual entre regiones y países.

Si bien el desarrollo de este derecho, en estrecha relación con el derecho a la vida privada, ha sido lento, los avances en la generación de criterios, la delimitación de su alcance, así como su relación con otros derechos humanos en contextos específicos, nos permiten suponer que la aducida falta de experiencia para su reconocimiento no es ya un argumento viable en la actualidad. Es necesario generar estándares comunes que permitan proteger de manera efectiva a las personas con una aproximación universal, para garantizarle el mayor disfrute de sus derechos y libertades, así como para contribuir con el desarrollo económico y social en un marco de economía global digital y una sociedad interconectada como la actual.

\section{BIBLIOGRAFÍA}

Alexy, Robert, "Constitutional Rights and Proportionality", Revus, Journal for constitutional theory and philosophy of law, núm. 22, 2014, pp. 51-65.

Castro, D., "The False Promise of Data Nationalism", en The Information Technology E Innovation Foundation, diciembre de 2013.

Cate, Fred H. y Mayer-Schönberger, V., "Data Use and Impact Global Workshop", Center for Applied Cybersecurity Research, Indiana University, 2013.

, Notice and Consent in a World of Big Data: Microsoft Global Privacy Summit Summary Report and Outcomes, November, 2012.

Cate, F. H., Cullen, P. y Mayer-Schönberger, V., Data Protection Principles for the $21^{\text {st }}$ Century, Revising the 1980 OECD Guidelines, March, 2012.

De Hert, P. y Gutwirth, S., "Data Protection in the Case Law of Strasbourg and Luxemburg: Constitutionalisation in Action", en Gutwirth, S. et al. (eds.), Reinventing Data Protection?, Springer, 2009. [Versión electrónica]

Gutiérrez, H.E. y Korn, D., "Facilitando the Cloud: Data Protection Regulation as a Driver of National Competitiveness in Latin America”, Inter-American Law Review, University of Miami School of Law, vol. 45, issue 1, 2014. 
Kikelly, U., "The right to respect for private and family life. A guide to the implementation of Article 8 of the European Convention on Human Rights", Human rights handbook, num. 1, Strasbourg. 2003.

Maqueo, M. y Moreno, J., "Implicaciones de una ley general en materia de protección de datos personales", Documento de Trabajo de la División de Estudios Jurídicos del Centro de Investigación y Docencia Económicas, núm. 64, marzo 2014.

Miller, A. R., The Assault on Privacy: Computers, Data Banks, and Dossiers, University of Michigan Press, 1971.

PIÑar Mañas, J.L., “¿Existe privacidad?”, en Protección de Datos Personales. Compendio de lecturas y legislación, México, Tiro Corto Editores, 2010.

Puente Escobar, A. (2008), "La Agencia Española de Protección de Datos como garante del derecho fundamental a la protección de datos de carácter personal”, Azpilicueta. Cuadernos de Derecho, núm. 20, 2008.

Roagna, I. (2012), "Protecting the right to respect for private and family life under the European Convention on Human Rights”, Council of Europe Human Rights handbook, Strasbourg, 2012.

SuÁrez Crothers, C., "El concepto de derecho a la vida privada en el derecho anglosajón y europeo", en Revista de Derecho (Valdivia), Vol. XI, diciembre 2000.

Warren, S.D. and Brandeis, L.D., "The Right to Privacy", Harvard Law Review, vol. IV, num. 5, December 15, 1890. 